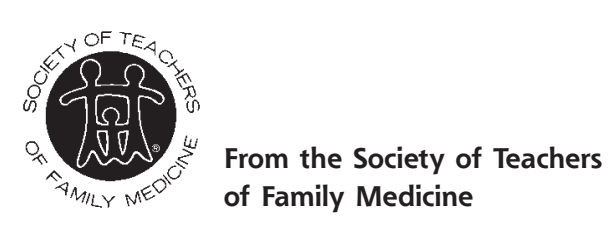

Ann Fam Med 2008:6;473. DOI: 10.1370/afm.895.

\section{A NEW, DYNAMIC RESOURCE FOR BOTH STUDENTS AND TEACHERS OF FAMILY MEDICINE: THE FAMILY MEDICINE RESEARCH WIKI AT FMDRL}

If you have ever wondered how to get started with a quality improvement project or how to pick the right statistical test for your data, or how to get your first research manuscript published, the Family Medicine Research wiki was designed for you. The wiki is a collaborative Web document that contains a growing collection of research methods related links, hints, resources, and guides. The content of the wiki can be viewed by anyone who has Internet access. You can get to the research wiki by using a search engine such as Google and typing in the search term "FMDRL research wiki" or you can find it by typing the following URL into your Internet browser: http://www.fmdrl.org/group/index.cfm?event=c. showWikiHome\&wikild=29. To edit or add to the wiki, you must first become a member of the FMDRL Group on Teaching Research in Residency.

Some of the valuable information you can find on the wiki includes tools for getting started in family medicine research; scholarly projects in residency training, IRB issues and participant safety; qualitative, quantitative, and other research methods; funding opportunities for family medicine research; and tips for disseminating your work (publishing and presenting).

Many of you have probably used the largest wiki on the Internet, Wikipedia, a user editable, Webbased encyclopedia that contains an astounding array of information. Just as any member of the Internet community can contribute to the Wikipedia, members of the family medicine research community can contribute to our research wiki. A wiki is a collaborative, dynamic document that is only as good as the contributions it gets from users. If you have a favorite Internet link for teaching a statistical method, or a document describing your residency scholarly project curriculum, we encourage you to add to the wiki.

The first step is to get a free account on FMDRL if you don't already have one, and check the box to join the Group on Teaching Research in Residency. Once you have logged into your FMDRL account, you will have editing privileges for the wiki. Editing or add- ing content to the wiki is almost as easy as using a word processor and our wiki has a page with detailed instructions about how to edit or add to the wiki. People who are new to wikis are sometimes reluctant to try editing the wiki for fear of breaking something, but the wiki tracks every change, so there really is nothing you can do to it that cannot be easily reversed. So, go ahead and make a contribution but be warned that wiki editing can be an addictive sport.

The Family Medicine Research wiki is housed in STFM's Family Medicine Digital Resources Library, http://www.fmdrl.org.

Caroline R. Richardson, MD, University of Michigan, STFM Research Committee

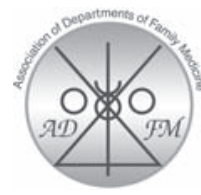

From the Association of Departments of Family Medicine

Ann Fam Med 2008;6:473-474. DOI: 10.1370/afm.893.

\section{RESIDENCY EDUCATION-COMPETENCY AND INNOVATION}

Family medicine residency programs must take the lead in educating physicians to practice evidencebased personalized medicine that achieves the highest standards of efficient quality care. Such physicians are needed to meet current health care needs, to expand medical care delivery capabilities for the baby boomer generation, and for emerging comprehensive models, such as the patient-centered medical home. ${ }^{1}$ For family medicine to succeed in meeting this challenge, greater flexibility to innovate as requested by the Future of Family Medicine Project must be granted to our residency programs by the residency review committees (RRC), the Accreditation Council for Graduate Medical Education (ACGME), etc. ${ }^{2}$ Currently, innovation can only be implemented if all existing requirements are met. This leaves little room for flexibility and new conceptual models of training.

Family medicine residency programs can be conceptualized to encompass 3 educational stages: foundation building, ambulatory competency, and enhancement tracks. The foundational and ambulatory stages are common to all programs. The foundational stage generally consists of 15 to 18 months education in core rotations such as pediatrics, medicine, obstetrics, surgery, and a combination of essential medical and surgical specialties largely taught in the hospital setting.

The development of ambulatory competency occurs simultaneously with the foundation stage and 